\title{
Penggunaan Tindak Tutur Dan Implikatur Pada Novel Yougisha $X$ no Kenshin karya Keigo Higashino
}

\author{
Ajeng Endah Adriana ${ }^{1^{*}}$, Renny Anggraenny ${ }^{2}$, Ni Made Andry Anita Dewi ${ }^{3}$ \\ ${ }^{[123]}$ Program Studi Sastra Jepang Fakultas Ilmu Budaya \\ ${ }^{1}$ [ajengendahadriana@yahoo.co.id] ${ }^{2}$ [anggraeny0309@yahoo.co.jp] \\ 3 [andry_anita@unud.ac.id] \\ *Corresponding Author
}

\begin{abstract}
The title of this research is "The Usage of Speech Acts and Implicatur in Yougisha X no Kenshin novel by Keigo Higashino". This research aims to determine the kind of speech acts and the meaning of implicatur contained in Japanese novel and used the Speech Acts Theory by Austin (1962) and Coorporation Maxim Theory by Grice (1975). The results of this research showed that there are four kinds of speech acts in Yougisha X no Kenshin novel by Keigo Higashino, such as locutionary act, illocutionary act, perlocutionary act and those three types of speech acts in one speech. The speech acts that often appears in Yougisha X no Kenshin novel is the illocutionary act. Furthermore, there are three kind of maxim in Yougisha $X$ no Kenshin novel, such as maxim of quantity, maxim of quality, maxim of relation and maxim of manner. Based on the results of this research, the maxim that often appears in Yougisha $X$ no Kenshin novel by Keigo Higashino are maxim of quantity and maxim of relation.
\end{abstract}

Keywords: speech acts, implicatur, coorporation maxim.

\begin{abstract}
Abstrak
Penelitian ini berjudul "Penggunaan Tindak Tutur dan Implikatur Pada Novel Yougisha X no Kenshin Karya Keigo Higashino”, bertujuan untuk menunjukkan bentuk tindak tutur dan makna implikatur yang terkandung dalam novel Jepang. Penelitian ini menggunakan teori Tindak Tutur Austin (1962) dan teori Maksim Kerja Sama Grice (1975). Hasil penelitian ini menunjukkan bahwa terdapat empat jenis tindak tutur yang terdapat dalam novel Yougisha $X$ no Kenshin karya Keigo Higashino, seperti tindak tutur lokusi, tindak tutur ilokusi, tindak tutur perlokusi dan tindak tutur lokusi, ilokusi dan perlokusi yang terdapat dalam satu tuturan secara bersamaan. Tindak tutur yang paling sering muncul adalah tindak tutur ilokusi. Selain itu, pada novel Yougisha $X$ no Kenshin karya Keigo Higashino terdapat empat buah maksim, seperti maksim kuantitas, maksim kualitas,maksim relevansi dan maksim pelaksanaan. Berdasarkan hasil dari penelitian ini, maksim yang paling sering muncul dalam novel Yougisha $X$ no Kenshin karya Keigo Higashino adalah maksim kuantitas dan maksim relevansi.
\end{abstract}

Kata kunci: tindak tutur, implikatur, maksim kerja sama

\section{(1) Latar Belakang}

Tindak tutur dan implikatur berperan penting dalam sebuah percakapan, oleh karena itu keberadaanya dinilai mutlak agar tercipta percakapan yang efektif antara penutur dan mitra tutur. Austin (1962) mengklasifikasi tindak tutur ke dalam tiga jenis, yaitu 
tindak tutur lokusi, tindak tutur ilokusi dan tindak tutur perlokusi. Tindak tutur lokusi (melakukan tindak tutur untuk menyatakan sesuatu), tindak tutur ilokusi (melakukan tindak tutur dalam menyatakan sesuatu) dan tindak tutur perlokusi (melakukan tindak dengan menyatakan sesuatu) merupakan tiga jenis tindakan dalam bidang pragmatik yang dapat diwujudkan oleh seorang penutur terhadap mitra tutur mengenai maksud kalimat yang diujarkan. Sementara itu, implikatur yang terdapat dalam percakapan merupakan pernyataan implikatif atau tersirat yang dimaksudkan berbeda oleh penutur dari yang sebenarnya dikatakan dalam suatu percakapan (Grice dalam Rahardi, 2005). Fenomena kebahasaan tindak tutur dan implikatur banyak ditemukan melalui percakapan antar tokoh dalam sebuah karya sastra. Salah satu diantaranya karya sastra Jepang dalam bentuk novel yang berjudul Yougisha $X$ no Kenshin karya Keigo Higashino. Terdapat penggunaan tindak tutur dan implikatur yang terdapat pada percakapan antar tokoh dalam novel tersebut.

\section{(2) Pokok Permasalahan}

Rumusan masalah dalam penelitian ini adalah sebagai berikut.

a. Bagaimanakah bentuk tindak tutur dalam novel Yougisha $X$ no Kenshin karya Keigo Higashino?

b. Bagaimanakahmakna implikatur akibat pelanggaran maksim kerja sama dalam novel Yougisha $X$ no Kenshin karya Keigo Higashino?

\section{(3) Tujuan Penelitian}

Secara umum, tujuan yang ingin dicapai dalam menganalisis novel
Yougisha $X$ no Kenshin karya Keigo Higashino adalah untuk menambah wawasan pembaca yang memiliki ketertarikan terhadap bahasa Jepang mengenai salah satu kajian bidang linguistik, yaitu pragmatik. Selain itu, secara khusus, tujuan penelitian ini adalah untuk mengetahui bentuk tindak tutur dan makna implikatur akibat pelanggaran maksim kerja sama.

\section{(4) Metode Penelitian}

Penelitian dilakukan secara kualitatif dengan metode deskriptif analisis. Teori yang digunakan adalah teori Tindak Tutur yang dikemukakan oleh Austin (1962,108-119) untuk menganalisis bentuk tindak tutur yang terdapat dalam novel Yougisha $X$ no Kenshin karya Keigo Higashino dan teori Maksim Kerja Sama yang dikemukakan oleh Grice (dalam Rahardi, 2005:53-59) yang digunakan untuk menganalisis makna implikatur dalam novel Yougisha $X$ no Kenshin karya Keigo Higashino.

\section{(5) Hasil dan Pembahasan}

Hasil dan pembahasan dari rumusan masalah bentuk tindak tutur dan makna implikatur akibat pelanggaran maksim kerja sama pada penelitian ini akan dijelaskan sebagai berikut.

\subsection{Tindak Tutur Lokusi dan Pelanggaran Maksim Kerja Sama}

Tindak tutur lokusi adalah tindak tutur yang digunakan untuk menyatakan sesuatu, yang umumnya berisi sebuah informasi (Austin, 1962:108). Dengan kata lain, tindak tutur lokusi menciptakan tuturan yang memiliki fungsi menyatakan atau menginformasikan tanpa membuat 
tuturan tersebut memiliki akibat. Adapun contoh analisis data sebagai berikut.
(1) Yasuko
Wakareta otto nan desu. kekkon shite nannen mo tatsu no ni, ima da ni tsukimatotte kurun desu. Okane wo watasanai to kaette kurenakute... Kyou mo sonna fuude shita. Mou gaman ga dekinakute, sore de katto naa...
Ishigami : Jishu suru tsumori desu ka.
Yasuko : Sou suru shikanai to omoimasu. Kankei no nai Misato ha hontou ni kawai sou nan desu kedo.

$\begin{array}{ll}\text { Yasuko : } & \text { Dia mantan } \\ & \text { suamiku. Kami } \\ & \text { sudah berpisah } \\ & \text { selama beberapa } \\ & \text { tahun, tapi belum } \\ & \text { lama ini dia } \\ & \text { meminta rujuk. } \\ & \text { Masalahnya, dia } \\ & \text { tidak mau pulang } \\ & \text { kalau tidak diberi } \\ & \text { uang dan hari ini } \\ & \text { juga begitu. Karena } \\ & \text { tidak tahan lagi, } \\ \text { akhirnya aku... } \\ \text { Ishigami } & \text { Kau akan } \\ \text { Yasuko } & \text { menyerahkan diri? } \\ & \text { Sepertinya hanya itu } \\ & \text { jalan satu-satunya. } \\ & \text { Tapi aku kasihan } \\ \text { pada Misato yang } & \text { tidak tahu apa-apa. }\end{array}$

Pada data (1) dapat dianalisis bahwa tuturan Yasuko yang pertama termasuk ke dalam kategori tindak tutur lokusi yang digunakan untuk menyatakan suatu informasi atau menyatakan sesuatu (an act saying somethings) (Austin,1962:108). Tuturan tersebut dapat dengan mudah dipahami karena sesuai dengan makna kata dan makna kalimat dalam kamus maupun berdasarkan kaidah sintaksinya. Tuturan pada data (1) diujarkan tanpa mengandung maksud tertentu atau pun memengaruhi mitra tutur dalam bertindak. Namun, tuturan Yasuko selanjutnya dapat dikatakan bahwa Yasuko tidak memberikan kontribusi yang sesuai dengan permintaan (Grice dalam Rahardi, 2005:53-59), karena Ishigami mengharapkan agar Yasuko menjawab pertanyaan dengan tuturan 'ya' atau 'tidak' tanpa menjelaskan keterlibatan Misato dalam kasus pembunuhan Togashi, sehingga terjadi pelanggaran maksim kuantitas yang menyebabkan makna implikatur bahwa Yasuko bertahan dengan keinginannya untuk menyerahkan diri kepada polisi, meskipun hal tersebut dapat membuat Misato ikut tertangkap.

\subsection{Tindak Tutur Ilokusi dan}

Pelanggaran Maksim Kerja Sama

Tuturan tidak hanya berfungsi untuk menyatakan suatu hal atau menginformasikan, tetapi tuturan juga dapat digunakan untuk melakukan sesuatu. Tindak tutur ilokusi adalah tindak tutur yang mengandung daya untuk melakukan tindakan tertentu dalam hubungannya dengan mengatakan sesuatu (an act of doing something in saying somethings) (Austin, 1962:116). Tindakan tersebut dapat berupa janji, tawaran, atau pertanyaan yang terungkap 
dalam sebuah tuturan. Adapun contoh analisis data sebagai berikut.

(2) Ishigami : Jiken ga okita koto wo kakusu ka, jiken to o futari no tsunagari wo kitte shimauka, nodochiraka da ne.

$\begin{array}{clr}\text { Misato } & : \text { Dekiru to } \\ & & \text { omoimasuka. } \\ \text { Yasuko } & : \text { Misato! Nani wo } \\ & \text { itteru no? } \\ \text { Misato } & \text { Okaasan ha } \\ & \text { damattete. Ne, dou } \\ & \text { desu ka. Dekimasu } \\ & \text { ka. }\end{array}$

Ishigami : Muzukashii ne. Demo fukanou ja nai.

Ishigami : Entah itu mengubur kasus ini ataupun menutupi keterlibatan kalian berdua, yang pertama kali harus dilakukan adalah menyingkirkan mayat ini.

Misato : Apakah itu bisa dilakukan?

Yasuko : Misato! Apa maksudmu?

Misato : Ibu diam saja! Bagaimana, Paman? Bisa atau tidak?

Ishigami : Sulit, tapi bukan berarti mustahil

Pada data (2) Tuturan Misato, yaitu dekiru to omoimasuka...'apakah itu bisa dilakukan?' mengandung tindak tutur ilokusi. Hal tersebut disebabkan penutur tidak hanya bertanya mengenai kemungkinan keterlibatan ia dan ibunya dapat ditutupi, melainkan penutur juga meminta mitra tutur, yaitu Ishigami untuk melakukan tindakan tertentu agar ia dan ibunya lepas dari incaran polisi. Namun, tuturan Misato tersebut membuat Yasuko terkejut, sehingga ia segera bertutur kepada Misato melalui tuturan Misato! Nani wo itteru no?...'Misato! Apa maksudmu?'. Tuturan tersebut merupakan tuturan yang tidak sesuai dengan topik pembicaraan sebelumnya (Grice dalam Rahardi, 2005:53-59), yaitu tentang permintaan Misato kepada Ishigami agar Ishigami membantu mereka dalam menyembunyikan kasus pembunuhan Togashi. Oleh karena itu, tuturan Yasuko dinilai melanggar maksim relevansi yang menyebabkan implikatur bahwa Yasuko bermaksud untuk menegur Misato agar berhenti meminta bantuan kepada Ishigami terkait kasus pembunuhan yang melibatkan Yasuko.

\subsection{Tindak Tutur Perlokusi dan Pelanggaran Maksim Kerja Sama}

Tindak tutur perlokusi adalah tindak tutur yang diutarakan dengan maksud untuk memengaruhi mitra tutur. Tindak tutur ini dapat dikatakan berhasil apabila mitra tutur menerima efek atau dampak dari tuturan, sehingga mitra tutur, sehingga mitra tutur melakukan tindakan berdasarkan isi tuturan penutur (Austin, 1962:117). Tindak tutur perlokusimenghasilkan efek pada perasaan, pikiran dan tindakan mitra tutur. Adapun contoh analisis data sebagai berikut.

(3) Ishigami : Okamase bento wo.

Yasuko : Hai, okamase hitotsu.

Arigatou gozaimasu.Kinou, donate ka okyaku san ga? 


\begin{tabular}{|c|c|}
\hline Ishigami & $\begin{array}{l}\text { Hanashi ha shinai } \\
\text { houga ii desu. Keiji } \\
\text { ga doko de mihatteru } \\
\text { ka wakaranai. }\end{array}$ \\
\hline Yasuko & Gomenasai. \\
\hline Ishigami & $\begin{array}{l}\text { Saya pesan satu } \\
\text { bento spesial. }\end{array}$ \\
\hline Yasuko & $\begin{array}{l}\text { Baik, satu bento } \\
\text { spesial. } \\
\text { kau } \\
\text { tamu? }\end{array}$ \\
\hline Ishigami & $\begin{array}{l}\text { Lebih baik } \\
\text { tidak } \\
\text { mengobrol. }\end{array}$ \\
\hline & $\begin{array}{l}\text { Bagaimana kalau } \\
\text { ada detektif yang } \\
\text { sedang mengawasi? }\end{array}$ \\
\hline asuko & : Maaf \\
\hline
\end{tabular}

Pada data (3) tuturan Ishigami Okamase bento wo...'Saya pesan satu bento spesial.'mengandung tindak tutur perlokusi yang disebabkan adanya efek atau dampak akibat tuturan mitra tutur (Austin, 1962:117). Efek atau dampak yang ditimbulkan dari tuturan Ishigami terbukti melalui tanggapan Yasuko yang memastikan kembali pesanan Ishigami sebagai tanda mengerti kemudian mengucapkan terima kasih. Sesaat setelah Yasuko menerima pesanan Ishigami, ia teringat bahwa kemarin ia melihat Ishigami kedatangan seorang tamu, hal itu membuat Yasuko penasaran dan tidak tahan untuk tidak menanyakannya kepada Ishigami saat itu juga. Namun, Ishigami menanggapi pertanyaan Yasuko melalui tuturan Hanashi ha shinai houga ii desu. Keiji ga doko de mihatteru $\mathrm{ka}$ wakaranai... 'Lebih baik kita tidak usah mengobrol. Bagaimana kalau ada detektif yang sedang mengawasi?'. Tuturan tersebut dinilai tidak mengandung informasi yang relevan dari topik pembicaraan mitra tutur sebelumnya (Grice dalam Rahardi, 2005:53-59), sehingga terjadi pelanggaran maksim relevansi yang menyebabkan implikatur bahwa Ishigami sedang berusaha mengalihkan topik pembicaraan dengan maksud menyadarkan Yasuko agar ia tidak terlihat akrab dengan Ishigami di depan umum dikarenakan ketakutan Ishigami terhadap para detektif yang mungkin saja berada di sekitar mereka.

\subsection{Tindak Tutur Mengandung Lokusi, Ilokusi, Perlokusi dan Pelanggaran Maksim Kerja Sama}

Pada penelitian ini, ditemukan empat buah data yang mengandung ketiga jenis tindak tutur.Tindak tutur tersebut, yaitu tindak tutur lokusi, tindak tutur lokusi dan tindak tutur perlokusi. Tindak tutur tutur lokusi adalah tindakan yang digunakan untuk menyatakan suatu hal, biasanya berisi sebuah informasi yang dapat mudah dipahami karena tuturan tersebut mengandung makna kata dan kalimat yang sesuai dengan kamus dan kaidah sintaksis. Tindak tutur ilokusi adalah tindak tutur yang memiliki daya untuk melakukan suatu tindakan dalam hubungannya mengatakan sesuatu. Tindakan tersebut dapat berupa janji, tawaran ataupun pertanyaan yang terungkap dalam sebuah tuturan. Sementara itu, tindak tutur perlokusi adalah tindak tutur yang diutarakan dengan maksud untuk memengaruhi mitra tutur agar mitra tutur melakukan tindakan berdasarkan isi tuturan penutur. Tindak tutur ini memberikan efek atau dampak terhadap pikiran, perasaan ataupun tindakan mitra tutur (Austin, 1962:108-119). Adapun contoh analisis data sebagai berikut.

(4) Kusanagi : Sono toki, o tonari no youso ha dou deshita ka.

Ishigami : O tonari? 
Kusanagi : Hanaoka san no heya desu.

Ishigami : Hanaoka san ga douka saretandesu $k a$.

Kusanagi : Ie, mata nan to mo. Sore de jouhou wo atsumete iru wake desu.

Ishigami :Yoku oboetemasen ga, tokuni kawatta koto ha nakatta to omoimasu yo.

Kusanagi : Bagaimana keadaan tetanggamu saat itu?

Ishigami : Tetangga?

Kusanagi : Maksudku apartemen Hanaoka-san.

Ishigami : Apa yang terjadi pada Hanaoka-san?

Kusanagi : Tidak ada apa-apa. Seperti yang tadi kujelaskan, aku hanya ingin mencari informasi.

Ishigami : Aku tidak ingat. Setahuku tidak ada yang aneh.

Pada data (4) Berdasarkan tindak tutur lokusi, yaitu tindak tutur yang digunakan untuk menyatakan sesuatu, yang umumnya berisi sebuah informasi (Austin, 1962:108), tuturan Sore de jouhou wo atsumete iru wake desu...'Seperti yang tadi kujelaskan, aku hanya ingin mencari informasi' yang dituturkan oleh Kusanagi mengandung sebuah informasi yang diakibatkan makna kata dan kalimat tuturan tersebut sesuai dengan makna kata dan kalimat dalam kamus dan kaidah sintaksis, sehingga tuturan tersebut dapat dengan mudah dipahami sebagai sebuah informasi.

Berdasarkan tindak tutur ilokusi, yaitu tindak tutur yang mengandung daya untuk melakukan tindakan tertentu dalam hubungannya dengan mengatakan sesuatu (an act of doing something in saying somethings) (Austin, 1962:116), tuturan tersebut tidak hanya ingin menginformasikan bahwa kedatangan Kusanagi ke apartemen Ishigami adalah untuk mencari informasi, tetapi tuturan tersebut juga mengandung maksud dan fungsi lain, yaitu Kusanagi menginginkan agar Ishigami membantunya dalam melengkapi informasi yang dibutuhkan polisi terkait dengan kasus pembunuhan Togashi yang melibatkan Yasuko. Fungsi tuturan tersebut dituturkan oleh Kusanagi adalah agar Ishigami tergerak untuk mengingat kembali kondisi Yasuko pada hari itu dengan cara memperjelas maksud kedatangannya, yaitu untuk mencari informasi mengenai keadaan Yasuko.

Sementara itu, berdasarkan tindak tutur perlokusi, yaitu tindak tutur yang menyebabkan mitra tutur melakukan tindakan berdasarkan isi tuturan penutur (Austin, 1962:117). Pada data tersebut diketahui bahwa Kusanagi menyatakan kepada Ishigami bahwa ia mendatangi apartemen Ishigami adalah untuk mencari informasi terkait dengan kasus pembunuhan Togashi yang melibatkan Yasuko. Kemudian tuturan tersebut ditanggapi Ishigami dengan mengatakan bahwa ia tidak mengingat dengan jelas keadaan hari itu dan merasa bahwa tidak ada sesuatu yang aneh terjadi dengan tetangganya yang bernama Yasuko. Berdasarkan tanggapan yang diberikan oleh Ishigami, tuturan Kusanagi dapat dikatakan berhasil dalam memengaruhi pikiran, perasaan dan tindakan Ishigami, sehingga Ishigami melakukan tindakan 
berdasarkan isi tuturan, yaitu dengan memberikan kesaksian.

Berdasarkan tuturan Ishigami yang menyiratkan bahwa ia tidak tahu kondisi Yasuko pada saat pembunuhan terjadi. Tuturan Ishigami tersebut mengandung suatu kebohongan karena Ishigami bertutur tidak sesuaidengan fakta yang ada. Berdasarkan fakta, saat pembunuhan terjadi, Ishigami mendatangi apartemen Yasuko dengan sengaja karena ia mendengar suara orang bertengkar dari apartemen Yasuko. Oleh karena itu, tuturan tersebut dinilai melanggar maksim kualitas disebabkan Ishigami melanggar maksim kualitas yang mengharuskan penutur bertutur berdasarkan bukti dan fakta yang ada (Grice dalam Rahardi, 2005:53-59). Pelanggaran maksim kualitas pada data (4) mengakibatkan implikatur bahwa Ishigami ingin para detektif tidak menemukan hubungan antara dirinya dengan kasus pembunuhan Togashi yang dilakukan oleh Yasuko, sehingga ia berdalih dengan mengatakan bahwa hari itu ia tidak ingat kondisi Yasuko karena merasa tidak ada hal aneh yang terjadi di apartemen Yasuko.

\section{(6) Simpulan}

Berdasarkan hasil penelitian yang telah diperoleh, dapat disimpulkan beberapa hal, yaitu pada novel Yougisha $X$ no Kenshin karya Keigo Higashino terdapat 16 data yang mengandung tindak tutur. Pada data tindak tutur tersebut terdapat pelanggaran maksim kerja sama yang mengakibatkan terjadinya implikatur. Tindak tutur yang sering muncul pada novel Yougisha $X$ no Kenshin karya Keigo Higashino adalah tindak tutur ilokusi yang menunjukkan fungsi atau maksud lain dari sebuah tuturan yang dituturkan. Hal tersebut disebabkan oleh budaya Jepang yang menganggap bahwa berbicara dengan menyatakan maksud secara langsung merupakan hal yang tidak sopan, sehingga beberapa tuturan pada percakapan antar tokoh dalam novel Yougisha $X$ no Kenshin karya Keigo Higashino dibuat samar dari maksud atau fungsi tuturan yang sebenarnya penutur inginkan. Selain itu, implikatur akibat pelanggaran maksim kerja sama banyak ditemukan pada pelanggaran maksim kuantitas dan pelanggaran maksim relevansi. Maksim kuantitas adalah maksim kerja sama yang mengharuskan penutur memberikan tanggapan sesuai dengan porsi informasi yang diminta oleh mitra tutur. Sementara itu, maksim relevansi adalah maksim kerja sama yang mengharuskan penutur mempertahankan topik pembicaraan yang sama dalam sebuah percakapan dengan mitra tutur, sehingga tuturan antara penutur dan mitra tutur dengan topik pembicaraan saling berhubungan.

Hasil analisis tindak tutur pada novel Yougisha $X$ no Kenshin karya Keigo Higashino berdasarkan teori tindak tutur yang dikemukakan oleh Austin (1962:108-119) terdapat 16 buah data yang terbagi menjadi 3 buah data tindak tutur lokusi berupa tuturan yang berisi pernyataan sebuah informasi, 5 buah data tindak tutur ilokusi berupa tuturan yang tidak hanya sebagai pernyataan informasi, tetapi juga dituturkan untuk melakukan suatu hal, 2 buah data tindak tutur perlokusi berupa tuturan yang memiliki dampak terhadap mitra tutur, sehingga mitra tutur melakukan tindakan berdasarkan isi tuturan, serta 6 buah data tindak tutur lokusi, tindak tutur ilokusi dan tindak tutur perlokusi berupa pernyataan informasi melalui tuturan dan tuturan tersebut digunakan untuk melakukan suatu hal yang kemudian memiliki dampak terhadap mitra tutur, sehingga mitra tutur melakukan tindakan berdasarkan isi tuturan.

Tindak tutur lokusi yang digunakan sebagai pernyataan informasi 
terdapat pada tuturan Sukoshi, o hanashi wo ukagawasete itadakitain desu... 'Ada sesuatu yang ingin kami tanyakan'. Tindak tutur ilokusi yang dituturkan untuk melakukan suatu hal terdapat pada tuturan Jaa, sushi demo torou. Shokuji, mada nan darou...' Kalau begitu, ayo kita makan sushi. Kau belum makan malam,kan?'. Tindak tutur perlokusi yang digunakan sebagai tuturan yang mampu memberi dampak terhadap mitra tutur terdapat pada tuturan Okamase bento wo...' Saya pesan satu bento spesial'. Selain itu, tindak tutur lokusi, tindak tutur ilokusi dan tindak tutur perlokusi yang terkandung dalam satu tuturan secara bersamaan, terdapat pada tuturan Kochira ha? mikakenai kao da na... 'Siapa kau? Aku belum pernah melihatmu'.

Selain itu, hasil analisis implikatur berdasarkan teori maksim kerja sama Grice dalam novel Yougisha $X$ no Kenshin karya Keigo Higashino (dalam Rahardi, 2005:53-59) terbagi menjadi 6 buah data pelanggaran maksim kuantitas yang diakibatkan oleh tuturan yang tidak memberikan informasi secara cukup dan memadai, seperti pada tuturan Sou suru shikanai to omoimasu. Kankei no nai Misato ha hontou ni kawai sou nan desu kedo...'Sepertinya hanya itu jalan satu-satunya. Tapi aku kasihan pada Misato yang tidak tahu apa-apa'. Terdapat 3 buah data pelanggaran maksim kualitas yang diakibatkan oleh tuturan yang tidak sesuai dengan fakta atau bukti-bukti yang jelas, seperti pada tuturan Shiranai hito desu ne...'Hmm, aku tidak mengenalnya'. Terdapat 6 buah data pelanggaran maksim relevansi yang diakibatkan oleh tuturan yang tidak memberikan kontribusi secara relevan tentang sesuatu yang sedang dipertuturkan, seperti pada tuturan Misato! Nani wo itteru no?...'Misato! Apa maksudmu?'. Selain itu, terdapat 1 data pelanggaran maksim pelaksanaan yang diakibatkan oleh tuturan yang tidak jelas, seperti pada tuturan Iya, socchi koso ki wo tsukawanaide kure... 'Ah, kau juga tak perlu repot-repot'. Hasil analisis tersebut mengakibatkan makna implikatur berupa bertanggung jawab atas perbuatan salah, menolak menjawab, menyembunyikan fakta, menegur, merendah, menyatakan pendapat, memerintah, meyakinkan mitra tutur, mengakrabkan diri, menduga dan menyatakan harapan.

\section{(7) Daftar Pustaka}

Austin, J.L. 1962. How To Do Things With Word. London : Oxford University Press.

Higashino, Keigo. 2016. Yougisha X no Kenshin. Jepang: Bungei shunjuu.

Rahardi, Kunjana. 2005. Pragmatik; Kesantunan Imperatif Bahasa Indonesia. Jakarta: Erlangga. 